\title{
Articles
}

\section{Attending to Clients' Psychological Needs During Career Construction Counseling}

Claudia Sampaio, Paulo Cardoso, Jerome Rossier, and

\section{Mark L. Savickas}

Attending to clients' psychological needs during career counseling merits more attention in career theory and practice. We describe how the elaboration of clients' needs during career construction counseling supports clients' problem formulation. After reviewing the literature on the psychology of needs, we present and illustrate an intervention strategy with a case example. Counseling vignettes from the initial counseling task of problem formulation illustrate how to facilitate clients' narrative symbolization of their emotional experiences and associated needs. We explain how this strategy contributes to deepening clients' understanding of their problems and facilitates both the rewriting of a career narrative and the construction of new career plans. Analysis of the possibilities and limits of this practice merits attention in career counseling process research.

Keywords: needs, career construction counseling, problem formulation, career counseling process, counseling tasks

The concept of needs applied to human experience usually refers to a lack of some gratification, either physiological (e.g., hunger, thirst; Hull, 1943; Maslow, 1954) or psychological (e.g., affect, recognition; Dawis, 2002; Savickas, 1995). The concept of psychological needs is central to understanding human motivation (Deci \& Ryan, 2000; Maslow, 1968; McAdams, 2008; Murray, 1938) because it addresses the question of why people do what they do. This is a familiar question for career counselors, guiding their efforts to support people in understanding why they make choices and design their lives in the way they do. In fact, clients' elaboration of their needs allows them to construct a sense of purpose and intentionality (Goncalves et al., 2009; White \& Epston, 1990). From the 1950s through the 1970s, many practitioners used a test battery to measure the motivational constructs of needs,

Cláudia Sampaio and Jérôme Rossier, Institute of Psychology, University of Lausanne; Paulo Cardoso, Department of Psychology, University of Évora; Mark L. Savickas, Department of Family and Community Medicine, Northeast Ohio Medical University. Cláudia Sampaio is now at Institute of Psychology, Federal University of Rio Grande do Sul. This study was supported by a Swiss Government Excellence Research Scholarship (Grant 2019.0118) and the Portuguese Foundation for Science and Technology (Grant UIDB/04007/2020). Correspondence concerning this article should be addressed to Cláudia Sampaio, Institute of Psychology, Federal 